\section{EL PROYECTO ARKIT. LA VIVIENDA COMO KIT DE MUEBLES}

PROJECT ARKIT. THE HOME AS A FURNITURE KIT

Francisco Javier Terrados Cepeda
RESUMEN El artículo hace una revisión sintética sobre algunas de las bases conceptuales del llamado "proyecto Arkit" así como moderna donde 10 aue entendemos como residenciales y construcciones reales. Una primera parte recorre ejemplos de viliention construido casi con exclusividad el espacio doméstico. Son los "muebles que construyen casas". En la segunda parte, el artículo reseña los seis proyectos de casas prefabricadas ligeras que se han concebido al amparo del concepto del "kit de muebles" con sistema de prefabricación abierta: las viviendas del CSCAE, el prototipo Campohermoso, el proyecto Arkit, la residencia de Tariquejo, el proyecto Solarkit y el proyecto Arkit 18, de los cuales han sido construidos y analizados el tercero y el quinto: Arkity yu varian

ales del sur de Europa a portación novedosa en el campo de la vivienda prefabricada ligera, adaptada a las condiciones ambien tamaño y la versatilidad del mobiliario y la escala de la habitación convencional. El proyecto Arkit permite disposiciones a elección del usuario y, como muestran los ejemplos explestos, adaplaciones a diferentos programa

SUMMARY The article makes a summary review of some of the conceptual bases of the "Arrtkit project" and their results as housing projects and real buildinoss. The first part covers examples of modern homes where what we understand as furniture, now rather gigantic in scale, has defined, and in some cases almost exclusively built, the domestic space. This is the "furniture which builds houses". In the second part, the article reviews the six light prefabricated housing projects that have been designed under the "kit furniture" concept as an open prefabbrication system: the houses of CSCAE (the Council of Architectural Colleges of Spain); the

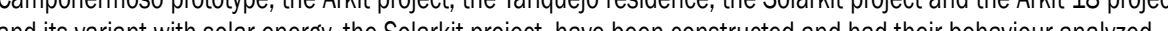

(t) thy of furniture and the scale of the conventional room. The Arkit project allows user choice and, as the examples show, adaptation to different housing programmes,

Persona de contacto / Corresponding author: terrados@arquired.es. Escuela Técnica Superior de Arquitectura. Universidad de

\section{ANTECEDENTES}

E n el ya clásico texto Home. A Short History of an Idea, Witold Rybczynski traza una particular hisde la configuración arquitectónica del hogar protagonismo frente la descripción de los avances de las instalaciones o los progresos del mobiliario "El mueble nos dice todo. Al igual que un paleontólogo puede reconstruir un animal prehistórico desce un fragmento de su mandíbula uno puede reconstruir el interior doméstico, y las actitudes de sus habitantes, desce una simple silla"1. Afirmaciones como ésta adornan un texto en el que el principal desarrollo de los argumentos se centra en el análisis del mobiliario de su ubicacín y de las instalaciones domésticas. En muchas ocasiones, se ha utilizado la metéfora de la "segunda piel" en referencia a la casa, entendida como el artilugio material que media entre el cuerpo humano y la naturaleza salvaje Sin embargo, siguiendo a Rybczynski, serín más bien los muebles esos primeros intermediarios entre el cuerpo y la naturaleza, por delante de la arquitectura misma. El mueble está antes, nos acoge, nos cobija sustenta los objetos que tocamos o que

1. Rybczynski, Witold: Home. A Short History of an Idea. New York: Penguin Books, 1990, pp 204 nos visten. Es la "segunda piel" más inmediata: primero (E) milario, luego la arquitectura.

Esta dialéctica entre mobiliario y edificio era extrema

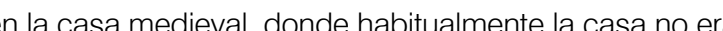
sólo el hábitat de la familia: era también un local de manufacturas, una tienda o un almacén y alojaba también parientes, siervos o trabajadores Los habitantes vivín dormían y comín en grandes espacios que se acomodaban a otros usos recolocando los muebles. El escenario de la vida doméstica era cambiante: el extremo contrario caso de las viviendas configuradas por habitaciones diversas y empaquetadas en zonas "funcionales" a las que hoy estamos acostumbrados. Se trataba de espacios únicos de generosas dimensiones en los que el mobiliario caracterizaba el espacio arquitectónico.

En La arquitectura de la vivienda unifamiliar, Arnaldo Cornoldi sostiene que "los modos de vida de la sociedad contemporánea (occidental) tienen su origen en la Gran Bretaña del siglo XVIII. De ella proceden los conceptos de privacidad, confort, (...) y es allí donde nace, con la burTuesía la vivienda moderna. Durante más de un siglo. las meiores casas se construveron al otro lado del Canal de 


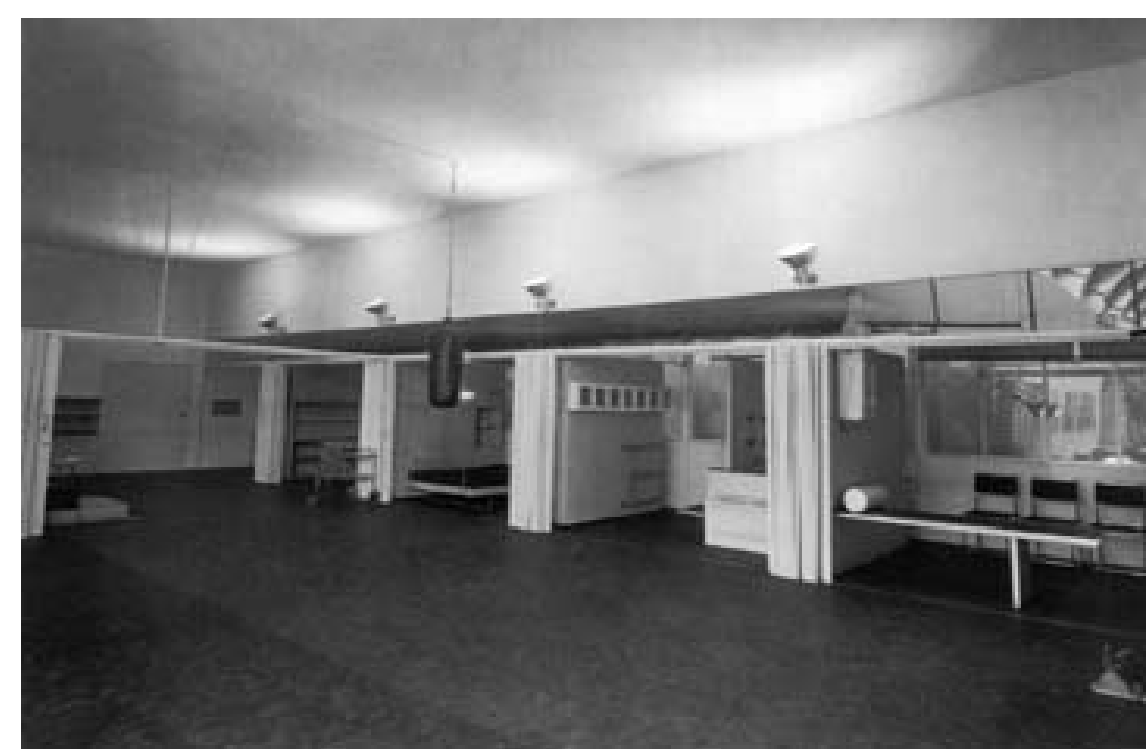

Mancha hasta que, a principios del siglo XX y partiendo de aquella experiencia, los arquitectos del viejo y nuevo continente la desarrollaron de forma más compleja y actual" En abierto contraste con el carácter "medieval" que podríamos asignar al mobiliario cambiante según usos, un rasgo específicamente distintivo de la casa anglosajon era que los principales elementos de lo que entendemos como mobiliario eran fijos (de hecho el término furniture no alude a la movilidad como característica esencial). Se diluye alli la frontera entre mobiliario y edificación, en contraste con lo que seguía ocurriendo en la cultura doméstca mediterránea y en gran parte de la Europa continenta donde predominaba el mueble como objeto cambiante en contraste con la arquitectura, inmóvil.

En la casa norteamericana, es fácil detectar la tradición del mobiliario fijo o empotrado (built- in) a partir los usos domésticos anglosajones y su preferencia por el mobiliario empotrado trasplantado al nuevo continente. Por otra parte, la casa norteamericana era fundamenta- mente obra de carpinteros. En algunas zonas, como de la costa oeste, se contaba además con el beneficio de la inmigración de excelentes carpinteros suecos y alemanes. Así, se puede concluir que el mobiliario fijo era una prolongación natural del trabajo de los carpinteros que construyen casas, que dota a éstas de una cierta ambgüedad entre lo que puede entenderse como arquitectura y lo que se muestra como mobiliario.

De esto sacó partido el desarrollo de la casa moderna norteamericana. Proliferan en ella los ejemplos en los que el interior doméstico puede ser leído como una sucesión

de espacios "conformados por muebles". Se trata en este caso (como la expresión "built- in" sugiere) de un tipo de mobiliario que se adosa a las paredes que definen los espacios, espesándolas y convirtiéndolas en muros huecos especializados. La posición del mobiliario es aquí subsidiaria de la distribución de los tabiques y muros que define el proyecto arquitectónico convencional

Hay que esperar a principios del siglo XX para encontrar propuestas en las que el mueble "arquitectónico" fijo deje de entenderse como adosado o "empotrado" a las paredes y se despliegue libremente, exento, dentro de la vivienda. La "puesta de largo" de los muebles como gerin tipo de espacio doméstico moderno ha sido señalada frecuentemente en relación con las propuestas de Ludwig Mies van der Rohe. La casa Tugendaht o la casa " 50 x 50" pueden interpretarse como surgidas del agigantamiento del mobiliario "de vitrina", una transito del abjeto expuesto hacia la arquitectura en el tiene mucho que ver la experiencia acumulada por Mies van de Rohe en el montaje de exposiciones. En el pabellón de Barce作 los se sustentan por objetos tratados como muebles que aparecen "expuestos" (mármoles, cortinas, armarios, cajas para cuartos de baño, etc)

. de Marcel Breuer, la Casa para un Deportista de la Exposición de la Construcción de Berlín de 1931 (figura experiencia del autor como diseñador ha crecido, con las particiones realizadas por los propio

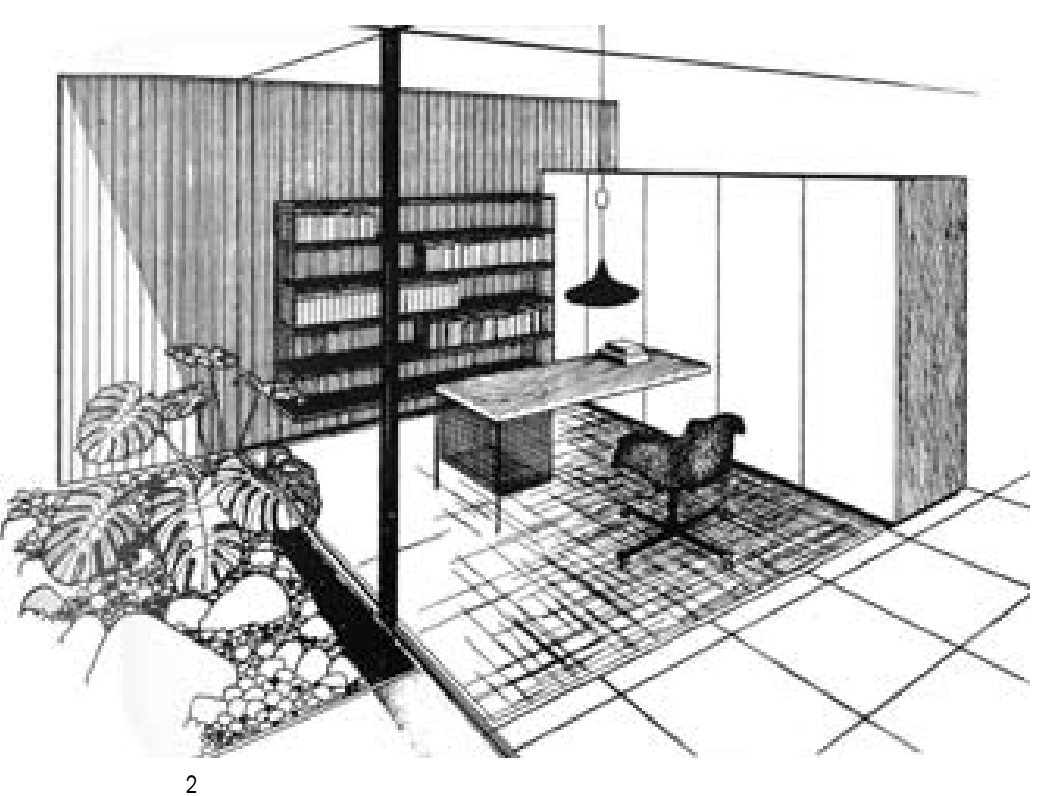

armarios y por los cierres móviles de librillo. Esta propuesta suele citarse junto con la casa modelo construida por Mies van der Rohe para la misma exposición, como los más claros precedentes de la estética de las Case Study Houses californianas, en cuyas plantas de distribución proliferan los muebles exentos de suelo a techo como elementos definidores del espacio

En el universo de las Case Study Houses (y en su reflejo en el medio oeste norteamericano en la obra de Keck \& Keck) son habituales las composiciones en las que definición arquitectónica de la casa se diluye en lo que aparenta ser un display de armarios, bancadas de cocina, parterres (bandas verdes), etc.: un tipo de espacio "expositivo" en el que el mobiliario se exhibe de forma exenta, tratado de forma abstracta. En muchas ocasiones las maquetas explicativas o las perspectivas de estos proyectos no contienen ninguno de los elementos clásicos de definicion del espacio: no hay fachadas, ni techos ni tabiques, sôlo muebles dispuestos estratégicamente. Asimismo las perspectivas interiores descriptivas de las casas están imbuidas de esta visualidad "de exposición". No hay mas que mobiliario en las perspectivas de la Case Study House 2, de Summer Spaulding y John Rex (1945). En la CSH 3, construida en 1949 por William W. Wurster y Theodore Bernadi, los pabellones que integran la casa se pueden leer como grandes muebles anclados por la chimenea, ella misma otro objeto exeno. Las perspectivas explicativas de la CSH 177 (igura 2), de Craig Ellwood (1955) sólo muestran mobiliario Esta manera de diseñar el espacio contamina incluso el tratamiento de los elementos de ajardinamiento: en la CSH 9, de Charles Eames y Eero Saarinen (1949) no sólo el mobiliario, sino unas bandas verdes

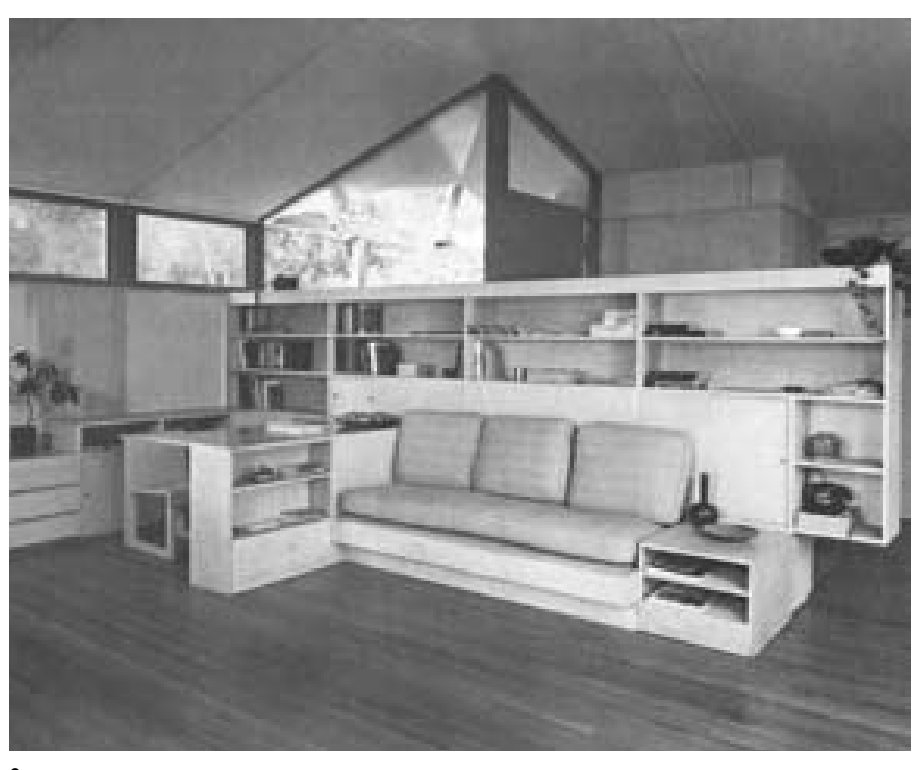

empaquetadas con las mismas dimensiones de los armarios colaboran en la definición de los espacios. La CSH 22, de Pierre Koenig, ya de 1959, puede fácilmente leerse como un conjunto de muebles más o menos gruesos agrupados bajo una estructura ligera Es probable que en el tratamiento del mobiliario buitt in en los proyectos residenciales de Richard Neutra anteriores a 1940 estuviera también otro precedente de esta manera de componer. En la casa VDL, de 1932, los dormitorios fueron diseñados como camarotes de barco, con todo el mobiliario empotrado.

Gregory Ain, que fue discípulo de Neutra, desplego unos sistemas espaciales en las viviendas donde los "muebles fijos" como configuradores del espacio van tomando protagonismo progresivamente. En la casa Daniel, obra de 1939 (figura 3), el espacio de la zona de día se articula en torno a un mueble central multiuso, en un distribución que anticipa hallazgos posteriores de Schindler. Su primera propuesta de casa prefabricada data de 1940: se compone de cuatro esquinas de hormigón pretabricado de 8 pies de alto, formando un cuadrado de 20 $\times 20$ pies. Sin particiones, sólo compuesta de mobiliario built in, la maqueta con la que se explica el proyecto es muy explicita en esa idea de componer "a base de muebles". De estas investigaciones son herederos casi todos los proyectos domésticos construidos por Schindler, como la promoción residencial "Mar Vista", construida en 947 entre Culver City y Venice Beach.

Operando como un reflejo en el medio oeste de las propuestas californianas, los hermanos Keck de Chicago insisten y depuran esta estrategia compositiva, que lega a ser en algunos casos una forma de construir: as se muestra en las imágenes de la puesta en obra de la 


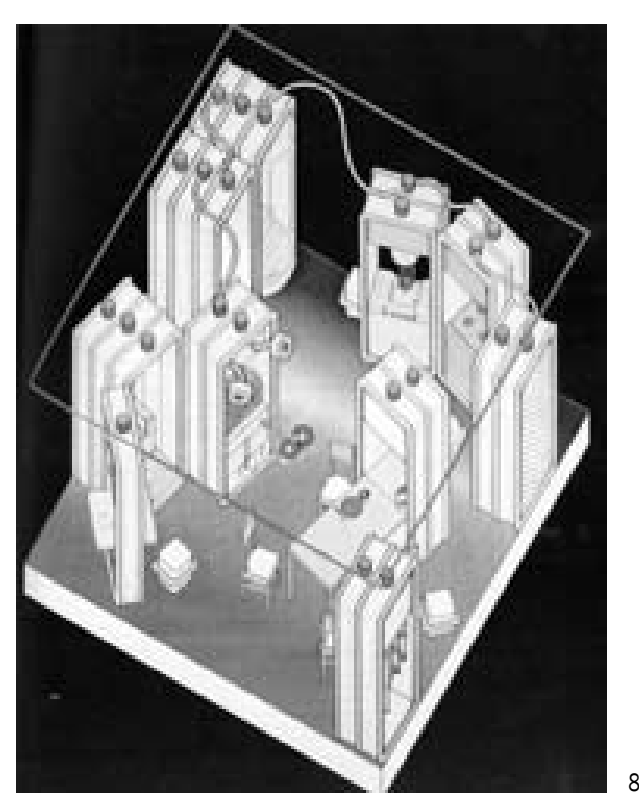

4. 5. Casa Loewy, Palm Springs, Albert Frey. 1946 6. Maqueta para el proyecto de Casas Metál. 7. Can Eicher X $X-100$, Paro Ato (Clifomia) A. Quincy Jones. 1957

8. Ettore Sottsass Ji, propuesta para la exposicion
taly: The New Domestic Landscape. 1972.
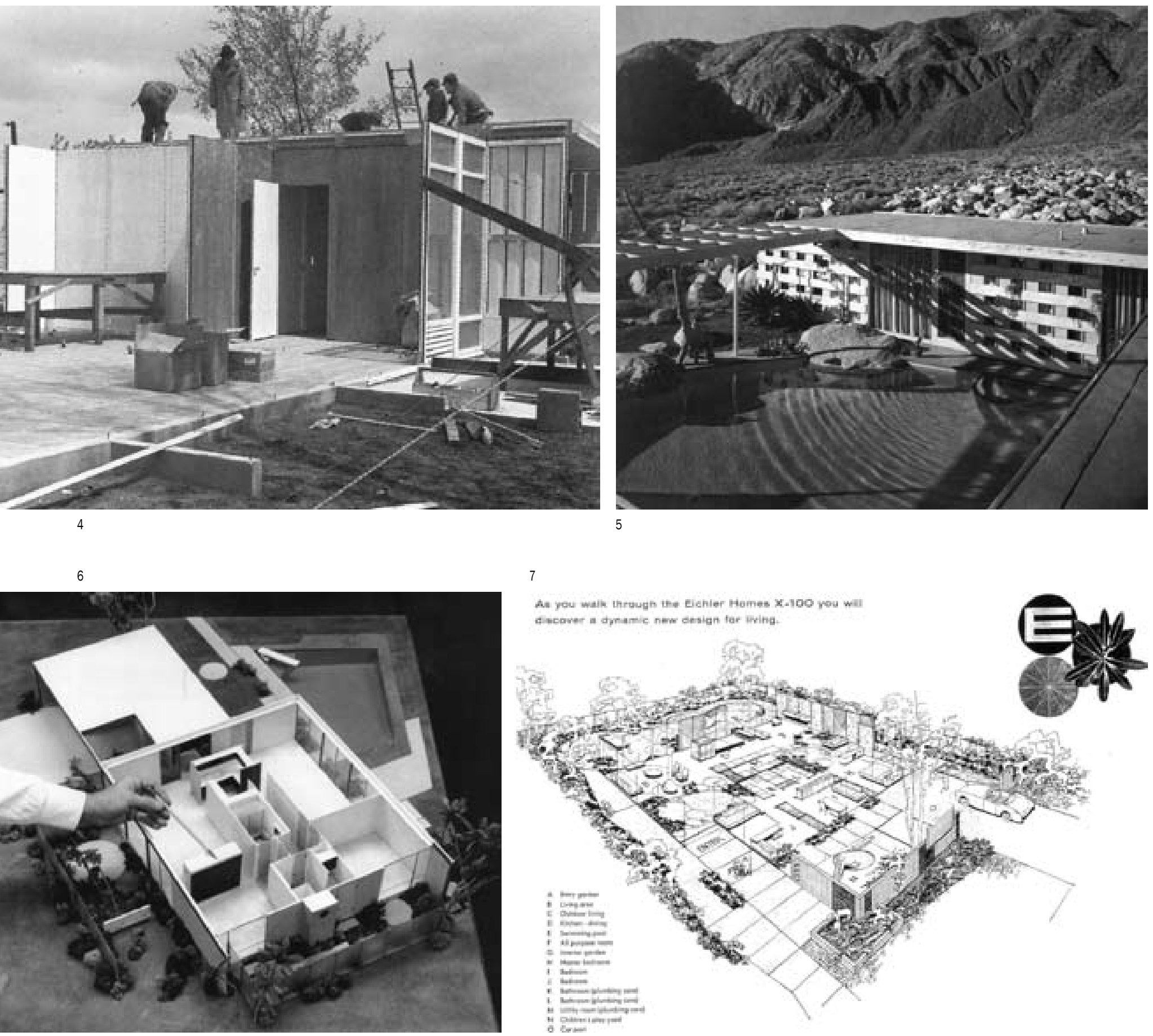

PROYECTO, PROGRESO, ARQUITECTURA

vivienda "prefabricada" denominada Green's Ready Built (figura 4), de 1946. Los operarios montan manualmente los paneles de cerramiento de las fachadas, no mucho más altos que ellos, con la naturalidad de quien ensarta en las bisagras la puerta de un armario.

También en California, pero fuera del círculo del editor Entenza y de los proyectistas de las Case Study Houses, Whitney Smith y Wayne Williams proponen en 1958 la casa prefabricada que denominan Plyformium que puede describirse como un pabellón cuadrado bajo una cubierta metálica a cuatro aguas de poca pendiente sobre un conjunto de muebles que compartimentan los espacios, eso sí con el auxilio de una estructura perimetra formada por delgados pilares metálicos.

En el ámbito de San Francisco, el referente de esta tendencia es A. Quincy Jones. En la San Diego Home, de 1948, una casa modelo para un constructor local hay un variado e imaginativo desarrollo del mobiliario fijo de contrachapado. También es pródiga en ejemplos la zona desértica de Palm Springs. La casa para el diseñador Raymond Loewy, de Albert Frey (1946), es un exponente depurado del modelo del techo flotante apoyado sólo sobre muebles: las particiones se configuran con tablero de madera de ciprés y los cerramientos se ejecutan con una celosía- estantería de contrachapado, en cuyos recuadros se insertan unos bloques traslúcidos que sirven de fondo a la colección de vasos y jarras de Loewy. El cerramiento es un auténtico aparador- vitrina a través del que se modula la relación entre el interior y el exterior (figura 5). En la casa del arquitecto William Burgess, de 1945, una cubierta ligera sobre delgados pilares metálicos se extiende sin límite. Los cerramientos y divisiones son muebles, paños de cristal o roca "domesticada" de Palm Springs. La casa se diluye como objeto y desde el exterior

sólo se percibe como una sombra geométrica rodead de un oasis arbóreo. En la casa para J. B. Shamel, en Eldorado, de William F. Cody (1961), encontramos de nuevo la cubierta ligera sobre muebles donde la estrucura portante está llevada al límite de ligereza. Las casas "metalicas" de Palm Springs (figura 6), de Wexler y Ha mison (1962) fueron prototipos patrocinados por la U.S. display maqueta en la que se muestra el proyecto Us básica de esta estrategia es obviar la sección del proyecto. Los muebles han de mostrar la ilusión de movilidad de disposición libre y cambiante, el espacio ha de aparecer fluido como el de una sala de exposiciones, el contendor ha de ser neutro: una bandeja y una cubierta sin accidentes donde las piezas deslizan, no hay sección solo dos planos paralelos: el juego arquitectónico se agota en la disposición en planta de los muebles definidores.

La perspectiva de la casa X-100 (figura 7), que A. Quincy Jones construyó para el promotor Eichler en 1956 es un paisaje de mobiliario sin límite preciso. La arquitectura esta totalmente disuelta, invisible en un territorio sólo deinido por los muebles, los parterres, los pavimentos y e ajardinamiento exterior. El coche es un objeto más, ordenado en el mapa. Viene a la memoria la definición que Pau Virilio de la vivienda originaria, que "no era en su origen más que el aparcamiento de los muebles del nómada". Independientemente de estos antecedentes norteamericanos, la formulación más acabada de un espacio enteramente conceptualizado a partir de muebles contenedores de diferentes equipos y prestaciones se pudo contemplar en las propuestas e instalaciones construidas psicion del Museo de Arte Moderno de (t)

3. Salazar, Jaime y Gausa, Manuel: Singular Housing. El dominio privado. Barcelona: Actar, 1999, pp 104. 


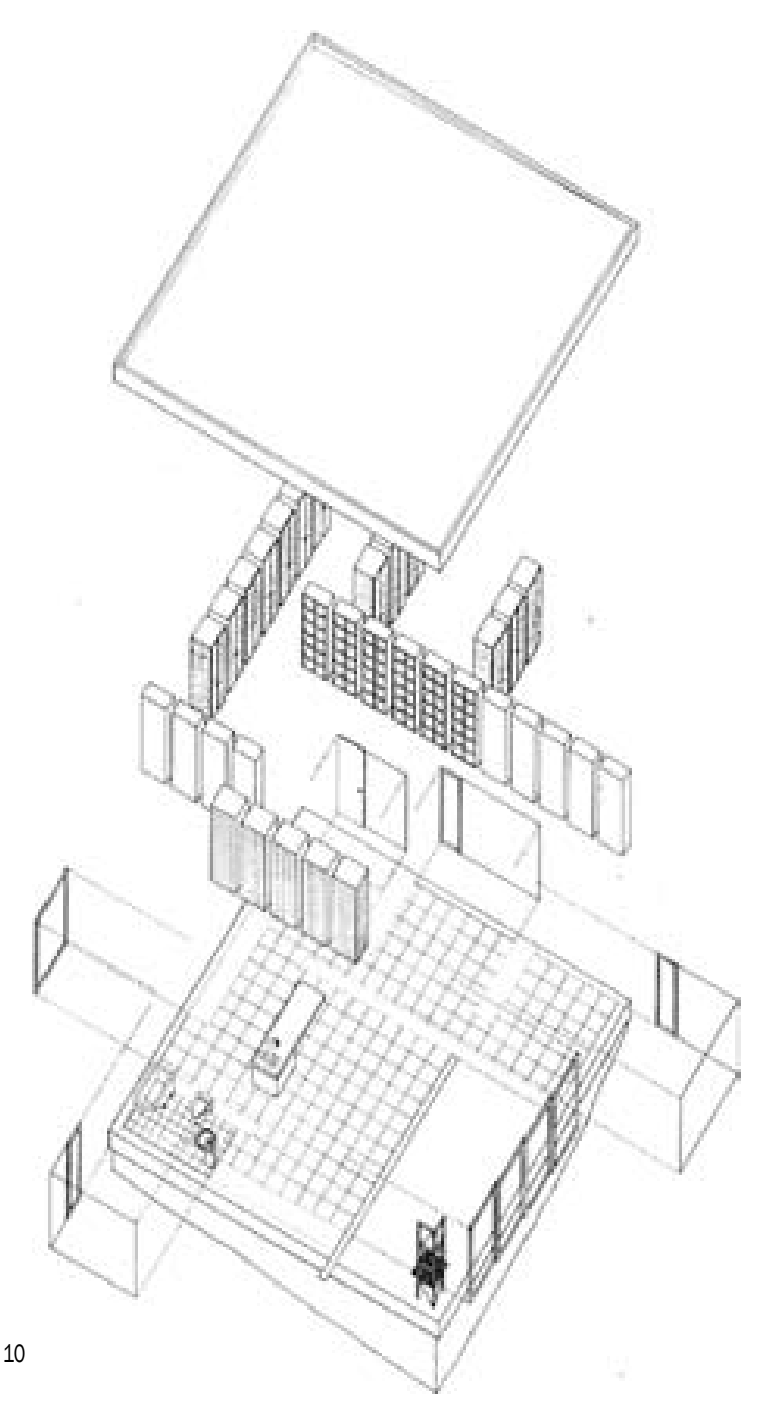

9. A Living Proposs
tion, Toyo Ito. 1988

gano), Shigeru Ban. 1995.

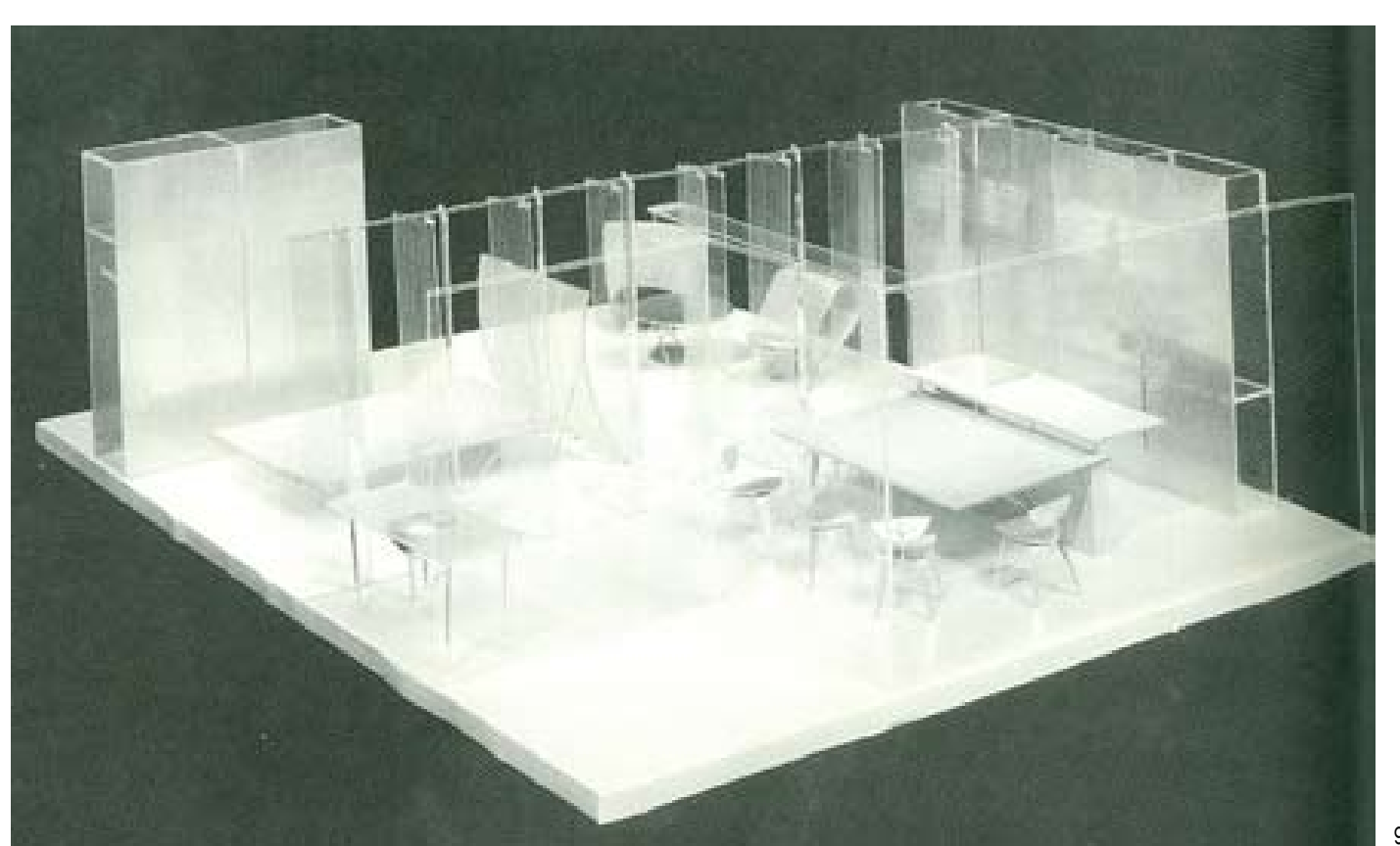

Doce diseñadores italianos desarrollaron propuestas de "entornos domésticos" totalmente conformados a partir de piezas de mobiliario, preferiblemente fabricados con herentes con el concepto de "muebles que construyen la casa" resultaban la propuesta construida por Ettore Sottsass Jr., a partir de armarios plásticos del mismo tamaño y con diferente contenido (adaptado a cada uno de los usos domésticos), y el proyecto teórico de Gianantonio Mari, donde los componentes- mueble define muros huecos compactos que terminan por conformar habitaciones completas.

En 1988, como arranque de un conjunto de actividades encaminadas a conmemorar el legado del program de las Case Study Houses, el Museo de Arte Contemporáneo de Los Ángeles invitó a seis arquitectos y diseñadores a presentar una propuesta de casa prototipo experimental, que debiera responder al espiritu de época, al modo como en los cuarenta el editor Entenza alumbró el programa de las CSH. De las seis propuestas merece la pena destacar la de Toyo Ito ("A Living Proposal for the Silver Generation" (figura 9)). Se trata de una recreación, en clave minimalista, del sistema composiquerido a los arquitectos del programa de Entenza, pero este caso ajustados a un programa de usos mínino. Esta forma de componer llevó a otro japonés, Sigheru Ban, a la escena internacional. En las Furniture Houses 1 , 2 y 3 (1995-96) (figura 10) se alude a los componentes "muebles" de una forma explícita. En la FH 1 se materializa un esquema tal vez deudor de la CSH de Toyo Ito pero con toda seguridad heredero de los precedentes californianos (de hecho éstas y otras viviendas unifamiliares de estos años son denominadas "Case Study Houses" por el autor). En las FH 2 y 3 se aborda la construcción de la casa de dos plantas. El sistema constructivo pierde aquí su claridad conceptual ya que se hace necesario un esqueleto estructural convencional para sustentar los pisos. El desarrollo más coherente del sistema hubiera sido, sin embargo, seguir usando los elementos de mobiliario como "muros de carga", al modo de lo que se produce en laFH 1. Según el testimonio del propio autor referente a su proceso creativo, es la propia experiencia constructiva con proyectos anteriores la que le hace desembocar en las "casas mueble". "En la 'Librería de un Poeta' creé estructuras tipo Vierendeel en forma de pórticos hechos de tubos de papel y en su interior introduje estanterías autoportantes para libros (...). Me di cuenta de que las librerías
PROYECTO, PROGRESO, ARQUITECTURA eran tan capaces de sustentar el tejado como las estructuras de tubos de papel. Toda esta experimentación me "levó al desarrollo de la Furniture House"

\section{EL PROYECTO ARKIT}

Antecedentes arquitectónicos como los hasta aquí expuestos sirvieron como base conceptual para la formulación del concepto del "kit de muebles" como nuevo sistema de producción de viviendas prefabricadas ligeras para el ámbito del Sur de España que se empezó a definir a partir de 2003 El concepto fue enunciado en la memoria del proyecto de la siguiente forma: "si en vez de pensar la casa prefabricada como la suma de paredes más techo o como un conjunto de habitaciones o recintos más o menos prefijados, la descomponemos en las funciones menudas que la vida diaria desempeña, tales como comer, dormir, ver la televisión, lavarse, almacenar ropa... (todas las que imaginemos) y asociamos a cada una de ellas a un mueble, el cual se consfruye con dimensiones compatibles para el ensamblaje con otros, podemos concebir la vivienda industrializada como una asociación de mobiliario más que como un contenedor

4. Bell, Eugennia (Ed.): Shigeru Ban. Nueva York: Princeton Architectural Press, 2001, pp X. arquitectónico y podemos imaginarla como algo confortae, atractivo y participativo, inc/uso divertido".

"Algunos muebles desmontables que adquirimos en as grandes superficies comerciales tienen casi el tamaño de la pared de una habitación. Compramos tableros precortados y conectores, seguimos las instrucciones y armamos piezas de una considerable dimensión: casi habitaciones. En el otro extremo, la casa industrializada ligera suele ser de una planta, como mucho de dos. Con alturas de techo que casi se tocan con la mano: casi muebles". Las primeras fases de diseño del sistema tuvieron lugar entre enero y diciembre de 2003. La primera operación fue conceptual: se trataba de llevar a cabo materialmente la premisa del concepto, asociar a las diferentes actividades domésticas un mueble y dimensionarlo con medidas compatibles para su asociación. Se establecieron unas reglas de juego: las piezas prefabricadas tendrían una unica medida en vertical, la altura libre de una vivienda social $(2,40 \mathrm{~m})$, y se conformarían sobre la base geométrica de una caja con costados perpendiculares al fondo de solar para conseguir su asociación por adición contigua. 

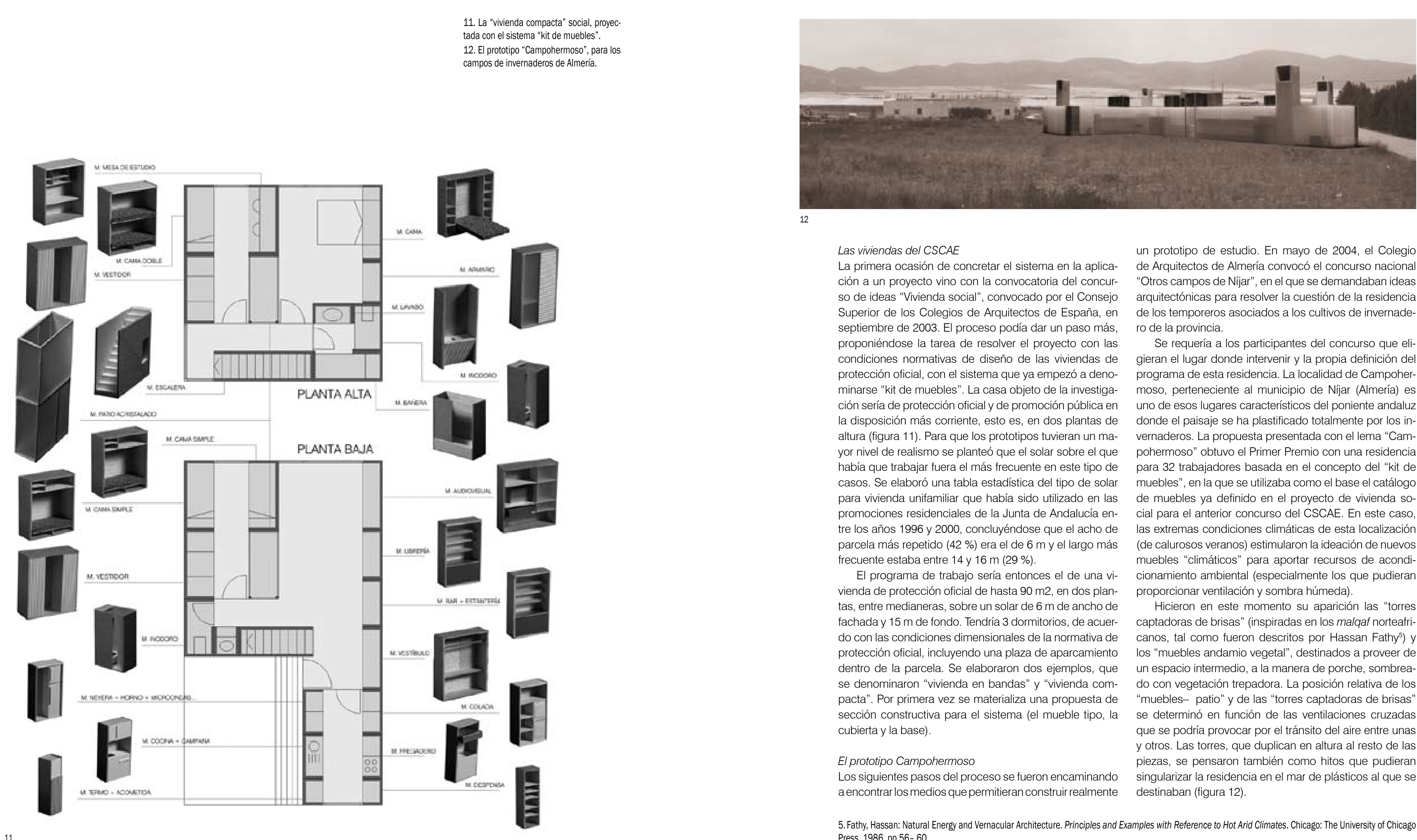

Las viviendas del CSCAE

de concretar el sistema en la aplicación a un proyecto vino con la convocatoria del concurco de ide " "Vivioncla socil", convocado por el concurSuperior de los Colegios de Arquitectos de España en septiembre de 2003 . El proceso pol'́a dar un paso más, proponiéndose la tarea de resolver el proyecto con las condiciones normativas de diseño de las viviendas de protección oficial con el sistema que ya empezó a denominarse "kit de muebles". La casa objeto de la investigción sería de protección nficial y de promoción pública la disposición más corriente, esto es, en dos plantas de altura (figura 11). Para que los prototipos tuvieran un mayor nivel de realismo se planteó que el solar sobre el que había que trabajar fuera el más frecuente en este tipo de casos. Se elaboró una tabla estadística del tipo de solar para vivienda unifamiliar que habí sido utilizado en las promociones residenciales de la Junta de Andalucía entre los años 1996 y 2000 , concluyéndose que el acho de parcela más repetido (42\%) era el de 6 my el largo más frecuente estaba entre 14 y $16 \mathrm{~m}$ (29\%).

El programa de trabajo sería entonces el de una vivienda de protección oficial de hasta $90 \mathrm{~m} 2$, en dos plantas, entre medianeras, sobre un solar de $6 \mathrm{~m}$ de ancho $\mathrm{de}$ fachada $15 \mathrm{~m}$ de fondo Tendría 3 dormitorios, de acuerdo con las condiciones dimensionales de la normativa de protección oficial incluyendo una plaza de aparcamiento dentro de la parcela. Se elaboraron dos ejemplos, que se denominaron "vivienda en bandas" y "vivienda compacta". Por primera vez se materializa una propuesta de sección constructiva para el sistema (el mueble tipo; cubierta y la base).

El prototipo Campohermoso

Los siguientes pasos del proceso se fueron encaminando eencontrar los medios que permitieran construir realmente

5. Fathy, Hassan: Natural Energy and Vernacular Architecture. Principles and Examples with Reference to Hot Arid Climates. Chicago: The University of Chicago 5. Fathy, Hassan: Natural
Press, 1986, pp 56- 60 . un prototipo de estudio. En mayo de 2004, el Colegio de Arquitectos de Almería convocó el concurso naciona "Otros campos de Nijar", en el que se demandaban ideas "rquitectónicas para resolver la cuestión de la residencia de los temporeros asociados a los cultivos de invernadee la provincia.

Se requería a los participantes del concurso que elgieran ellugar donde intenveniry la propia definición de programa de esta residencia La localidad de Campoher moso, perteneciente al municipio de Nijar (Almería) es uno de esos lugares característicos del poniente andaluz donde el paisaje se ha plastificado totalmente por los invernaderos La propuesta presentada con el lema "Campohermoso" obtuvo el Primer Premio con una residenci para 32 trabajadores basada en el concepto del "kit de muebles", en la que se utilizaba como el base el catálogo de muebles ya definido en el proyecto de vivienda social para el anterior concurso del CSCAE. En este caso, las extremas condiciones climáticas de esta localización (de calurosos veranos) estimularon la ideación de nuevos muebles "climáticos" para aportar recursos de acond cionamiento ambiental (especialmente los que pudieran proporcionar ventilación y sombra húmeda).

Hicieron en este momento su aparición las "torres captadoras de brisas" (inspiradas en los malqaf norteafricanos, tal como fueron descritos por Hassan Fathy ${ }^{5}$ ) los "muebles andamio vegetal", destinados a proveer de un espacio intermedio, a la manera de porche, sombreado con vegetación trepadora. La posición relativa de los "muebles- patio" y de las "torres captadoras de brisas" se determinó en función de las ventilaciones cruzadas que se podría provocar por el tránsito del aire entre unas otros. Las torres, que duplican en altura al resto de las piezas, se pensaron también como hitos que pudieran singularizar la residencia en el mar de plásticos al que se destinaban (figura 12). 


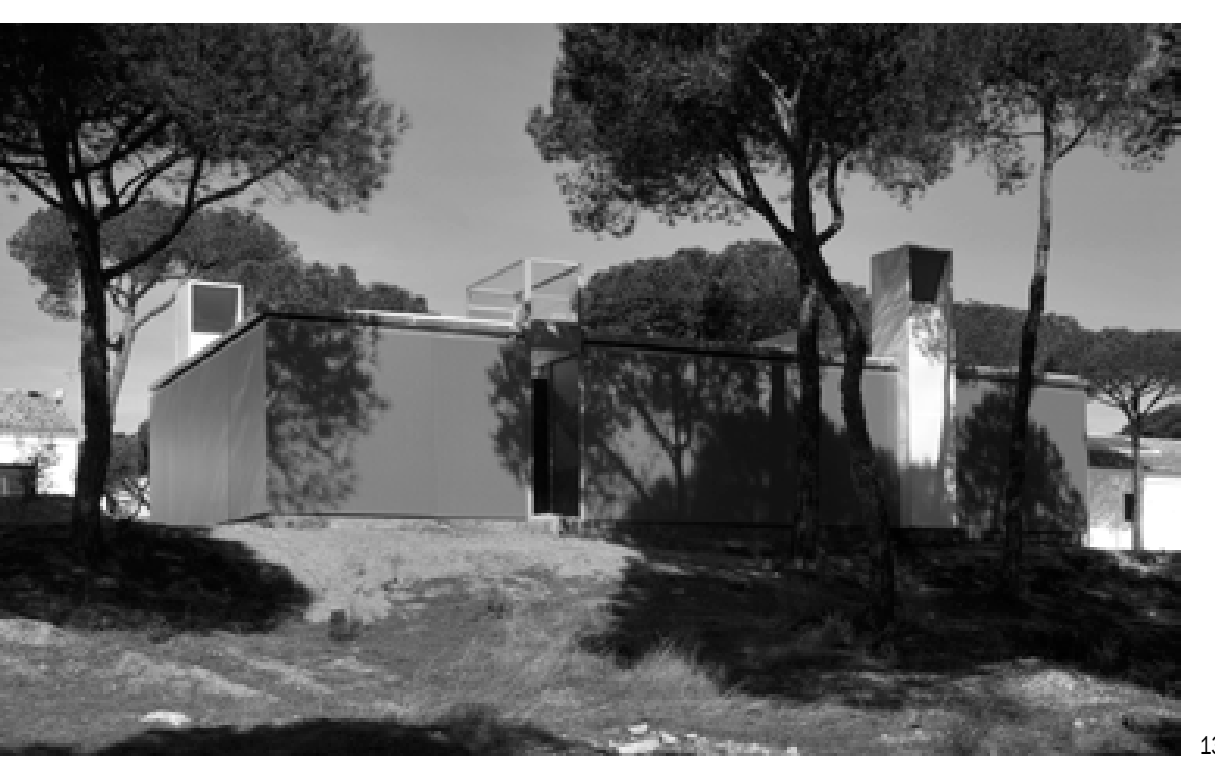

13. Vista exterior del prototipo Arkitit junto a 14. Vista interior del prototipo Arki.

15. La disposicíón del "kit de muebles" en
la Residencia ariquejojode Cartaya (Huelva)
El proyecto Arkit

El proyecto Campohermoso no llegó a materializarse pero sivió para respaldar la presentación de la propuesta de construcción de un prototipo en la $1^{a}$ convocatoria de subvenciones para actividades de investigación en materia de arquitectura y vivienda (junio de 2005) de la Consejería de Obras Públicas y Transportes de la Junta de Andalucía. La provincia de Huelva es uno de los principales focos de atracción de trabajadores agrícolas temporeros, en este caso vinculados a la recolección de la fresa, y el problema del alojamiento temporal de los trabajadores resultaba especialmente acuciante entre marzo y junio de cada temporada. Para que la propuesta presentada pudiera tener una ubicación real, se habían realizado gestiones previas con el Ayuntamiento de Cartaya (Huelva) a través de la asociación Huelva Acoge, con las que se consiguió disponer de los terrenos anexos al Albergue "Casa del Gato", de propiedad municipal, para construit en ellos el prototipo.

Por primera vez se utilizó (y se registró como marca) el término Arkit para nombrar el sistema. El prototipo a construir sería una versión reducida del proyecto Campohermoso, resultante de seleccionar una de las cuatro alas: una residencia (ya con la escala de vivienda unifamiliar) para 8 trabajadores temporeros (figuras 13 y 14). Incluiría dos patios y dos torres captadoras de brisas para mantener la secuencia de ventilaciones cruzadas que se buscaba en el prototipo de 32 trabajadores. Del anterior prototipo, el proyecto Arkit también conserva los muebles "andamio vegetal" en una posición que permitiera la creación de un porche vegetal exterior. Este porche saca partido de la disposición en "L" de la vivienda, generada por el encuentro de dos alas, una con la zona de noche y otra con la de día.

Obtenida la subvención, el montaje del prototipo en Cartaya se realizó entre el 24 de octubre y el 2 de noviembre de 2006.

La residencia de Tariquejo

Tras la construccion del prototipo Arkit, en octubre de 2006, el Ayunlamiento de Cartaya encargó al equipo investigador el estudio de una residencia desmontable para 500 trabajadores temporeros basada en el sistema del "kit de muebles". La residencia habria de ubicarse en a zona del término municipal de Cartaya conocida como Tariquejo, junto a la parcela donde el Ayuntamiento tenía prevista la construcción de un Albergue permanente. La residencia desmontable para 500 plazas (Ia "miniciudad de los temporeros" como fue denominada en aquel momento) ampliaría el Albergue en sus terrenos aledaños, en las épocas de recolección.

El modelo de unidad de habitación sería el de albergue comunitario con "pabellones" de noche y espacio compartidos de día. La configuración general de una instalación residencia de esa magnitud tuvo que utilizar recursos de diseño urbano para organizarse de forma legible. Así, las unidades de habitación se agruparían en manzanas de tamaño variable, de entre 30 y 70 ocupantes. Las manzanas se ordenan a lo largo de dos calles principales, paralelas a la vía de acceso y que arrancan desde una plaza principal, situada en este acceso y articulando la relación entre el albergue permanente y la miniciudad desmontable. En cada manzana, los pabellones de noche construyen el perímetro, quedando el núcleo ocupado por un pabellón central de mayor dimensión que contiene los comedores y las estancias. Entre el núcleo y el perímetro se proponían zonas ajardinadas, resguardadas de las vías principales por las propias edificaciones de noche (figura 15).

La iniciativa municipal de una gran residencia prefabricada contó con apoyos iniciales de la Administración andaluza y tuvo una cierta repercusión mediática, pero se encontro con que el marco normativo andaluz relacionado con las subvenciones oficiales para la construcción residencial no contempla el caso de la vivienda no permanente. EI Ayuntamiento no encontró cauces para financiar la iniciativa desde los programas de protección oficial o de ayudas a la creación de albergues y el proyecto no tuvo un desarrollo posterior.

El proyecto Solarkit

El éxito de la construcción del prototipo Arkit en Cartaya motivó que la iniciativa del siguiente paso corespondiera no el equipo investigador, sino a la entidad que hizo posible con una subvención aquella residencia para los pemporeros de la fresa. La Consejería de Obras Publicas y Transportes de la Junta de Andalucía fue la que impulso que, en septiembre de 2008, una propuesta de vivienda 


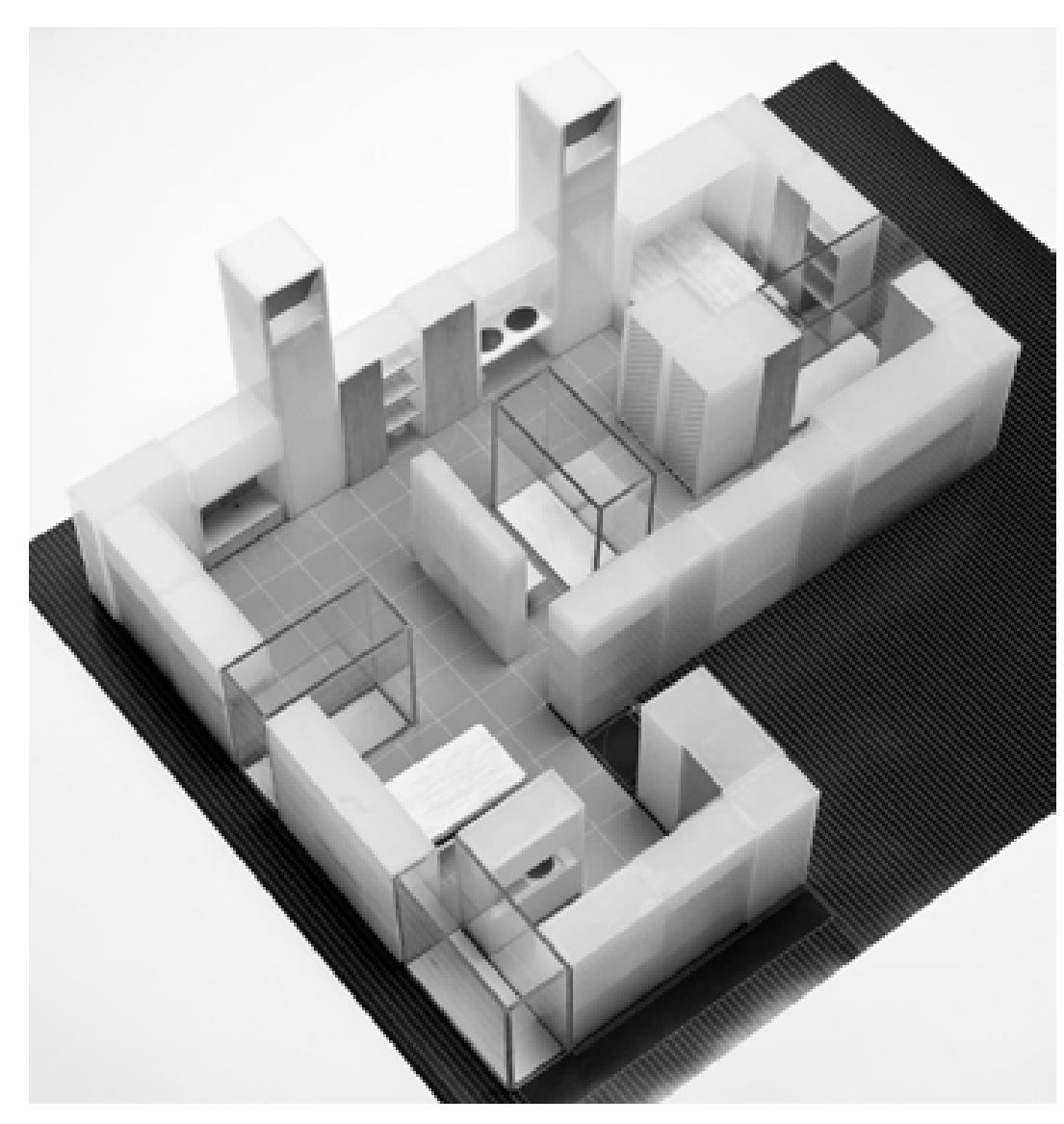

16. El proyecto Solarkit. Vivienda compacta 17. 4 personas.

8. Vista interior del popecto

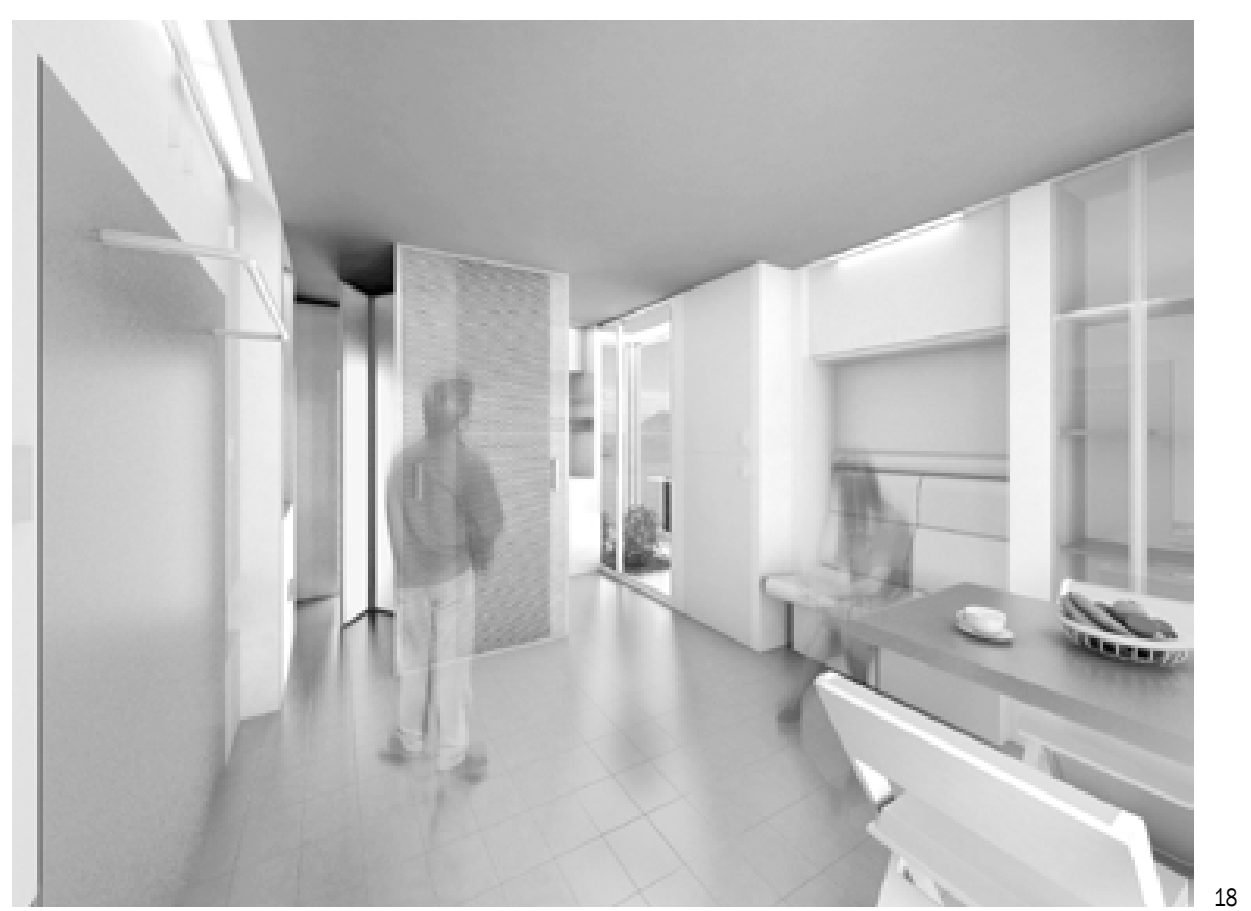

para 4 personas, prefabricada y autosuficiente energéticamente basada en el sistema del "kit de muebles" se presentara al concurso de admisión al evento Solar Decathlon Europe 2010.

Solar Decathlon Europe (SDE) es una competición internacional abierta a todas las Escuelas Técnicas y Universidades con colaboración con cualquier otra insfitución. Equipos universitarios compiten para diseñar construir y operar casas que funcionen únicamente con energía solar La competición SDE tuvo lugar en Madrid, en junio de 2010. Era la primera edición del evento en Europa como resultado de un Memorandum de Entendimiento firmado entre el Gobierno de Estados Unidos, a través del Departamento de Medio Ambiente, y el Gobierno de España a través del Ministerio de Vivienda Solar Decathlon se había celebrado ya anteriormente en cuatro ocasiones en Washington DC, en los otoños de 2002 2005, 2007 y 2009

Tras la presentación de la propuesta, en octubre de 2008 y representando a la Universidad de Sevilla, se recibió poco tiempo después la notificación de su selección para la participación en el evento. El proyecto Arkit pasaba a ser "Solarkit" ya que la casa propuesta tenía que contar con todos los sistemas que le permitieran ser totalmente autosuficiente energéticamente, abastecida por energía solar térmica y fotovoltaica (figuras 16 y 17). La selección para el evento implicaba el apoyo financiero para la construcción real. El desarrollo del proceso de diseño y de ejecución, muy exigente en cuanto a plazos y cantidad de documentación técnica, permitió avanzar extraordinariamente en el estudio y comprobación de las condiciones de habitabilidad del sistema y de su compatibilidad con las últimas tecnologías de las instalaciones domésticas, al mismo tiempo que elementos como "mueble captador de brisas" alcanzaba un nivel extremo " que al humedecerse provoca el enfriamiento evaporativo del aire de admisión.

El proyecto Arkit 18

Con posterioridad a la competición Solar Decathlon, y motivados por la necesidad de divulgar los resultados en ferias de la construcción y otros eventos, a partir de octubre de 2010, algunos de los promotores y colaboradores en la construcción del proyecto Solarkit encergaron un diseño de un pabellón expositivo que, de alguna manera mostrara los componentes del sistema. El primer evento al que acudir sería la feria Econstrucción 2010, de Sevilla. La propuesta de diseño fue no proyectar un stand al uso sino que aprovechando la ocasión y utilizando parte de los componentes del proyecto Solarkit, se trataba de disenary construir una vivienda para una persona o pareja de $18 \mathrm{~m}^{2}$ (figura 18)

La elección de la medida de $18 \mathrm{~m}^{2}$ no era casual, sino que se relacionaba con lo que se estaba gestando en las nuevas propuestas de normativa residencial andaluza como el módulo métrico asignado "por persona" en la vivienda social protegida (así, para 4 personas, la habitual 
de 3 dormitorios, tendría $72 \mathrm{~m}^{2}$ ). El reto era diseñar, con el sistema Arkit, un espacio de esas reducidas dimensiones que contuviera todas las prestaciones de una residencia habitual en la que una persona o incluso una pareja pudiera reconocer como cómoda y habitable.

\section{CONCLUSIONES}

El conjunto de acciones experimentales que se han englobado bajo la denominación genérica de "proyecto Arkit" fueron motivados por la intención expresa de explorar un camino de investigación académica en el campo de la arquitectura en el que la ejecución de las piezas propuestas formara parte del proceso de pensamiento.

Esto modo de proceder tiene algunas ventajas que están fuera del alcance de la investigación especulativa Ventajas que tienen que ver con un método de trabajo en el las ideas mas abstractas se puedan elaborar construyendolas. Se trata de "pensar con las manos", llegar a encontrar avances del pensamiento que surgen de trabajo material. Richard Senett (que ha aportado recien(emente una vision novedosa al asunto) describe al "aresano como un productor que "mantiene discusiones mentales con los materiales mucho más que con otras pen cuyo proceso de producción "están inte- diserta sobre "la mano que piensa", reivindica una época en la que "las ideas arquitectónicas se creaban en íntima interacción con la construcción real"8. De esta manera, la labor del artesano avanza allí donde la fricción con lo real convoca conceptos que no pueden articularse con el pensamiento meramente especulativo. Los trabajos $d$. proyectos y obras englobados bajo la denominación ge nérica de "Proyecto Arkit", aquí reseñados, ilustran este tipo de investigación operativa, basada en la ejecución material de sus premisas. Las conclusiones sobre viabilidad, idoneidad técnica o aplicación eficiente al espacio doméstico actual no serían tan completas si no se hubieran construido los prototipos.

Por otra parte, el examen de los antecedentes expuestos y de su huella en estos proyectos y prototipos actuales muestra cómo líneas de investigación lejanas en el tiempo, apuntadas en otras épocas y otros entornos de la modernidad, pueden seguir dando frutos en la actualidad. Podemos encontrar trazas de futuro en ejemplos arquitectónicos que, aunque por el hecho de figurar en la historia de la arquitectura se perciben caducos en demasiadas ocasiones, contienen bocetos de desarrollos posibles en épocas posteriores, cuando la tecnología disponible o las prioridades de la sociedad son ya otras.
6. Sennett, Richard: El artesano. Barcelona: Editorial Anagrama, S.A, 2009, pp 18.

7. Idem.

8. Pallasmaa, Juhani: The Thinking Hand. Existential and Emboidied Wisdom in Architecture. Chichester, (United Kingdom): John Wiley \& Sons Ltd, 2009, 64.

\section{Bibliografía}

Aguila García, Affonso del: Las tecnologías de la industrialización de los edificios de vivienda. Madrid: Colegio Oficial de Arquitectos de Madrid,

.

Bell, Eugenia (Ed.): Shigeru Ban. Nueva York: Princeton Architectural Press, 2001

Cornoldi, Adriano: La arquitectura de la vivienda unifamiliar. Manual del espacio doméstico. Barcelona: Editorial Gustavo Gili S. A. 1999.

Fathy, Hassan: Natural Energy and Vernacular Architecture. Principles and Examples with Reference to Hot Arid Climates. Chicago: The University of Chicago Press, 1986

Jodidio, Philip: Temporary. Architecture Now. Colonia (Alemania): Taschen GMBH, 2011.

Kostof, Spiro: A history of architecture Settinós and rituals. New York: Oxford University Press, Inc, 1995.

Mccoy, Esther: The Second Generation. Salt Lake City: Gibbs M. Smith, Inc., 1984.

La habitacín vacante. Gerona: Editorial Pre Textos, 2001

Padura, Manuel (Ed.): Spain architects. Housing 4. El Masnou (Barcelona): Manuel Padura S.L.. 2008

Pallasmaa, Juhani: The Thinking Hand. Existential and Emboidied Wisdom in Architecture. Chichester, (United Kingdom): John Wiley \& Sons Ltch

Rybczynski, Witold: Home. A Short History of an Idea New York. Penguin Books, 1990.

Salazar, Jaime y Gausa, Manuel: Singular Housing. El dominio privado. Barcelona: Actar, 1999.

Sennett Richard: El artesano. Barcelona: Editorial Anagrama S.A. 2009.

Smith, Elizabeth A. T. (Ed.): Blueprints for Modern Living. Cambridge, Massachusetts and London, England: The MIT Press, 1989.

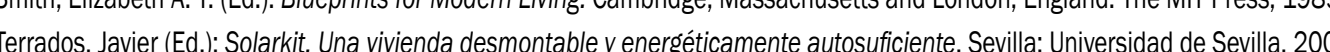
Vega Sánchez, Sergio (Ed.): Solar Decathlon Europe 2010. Towards Energy Efficient Buildings. Madrid: 10Action Project, 2011.

Wagener, Wolfgang: Raphael Soriano. New York: Phaidon Press Inc., 2002.

Wilk, Christopher: Marcel Breuer. Furniture and Interiors. New York: The Museum of Modern Art, 1981.
Francisco Javier Terrados Cepeda (Jaén, 1963) es arquitecto por la Escuela Técnica Superior de Arquitectura de Sevilla (1988) y Doctor Arquitecto por la misma (2011). Profesor Colaborador de Proyectos Arquitectónicos en la E.T.S.A. de Arquitectura de investigador destaca el provecto de Vivienda Desmontable Tipo Kit para timporers, Cartaya (Huelva) y el Proyecto Solarkit, construido por la Universidad de Sevilla para la Competición Solar Decathlon 2010 Su obra construida ha obtenido en los últimos años el Premio Nacional de la Vivienda Pública, el Premio Nacional Termoarcilla el Premio "Félix Hernández" del C.O.A. de de Córdoba, el $2^{\circ}$ Premio Nacional "Soluciones Urbanas", del C.S.C.A.E. y una de las tres menciones en el Premio Europeo de Arquitectura "Ugo Rivolta". 


\section{Autor imagen y fuente bibliográfica de procedencia}

Información facilitada por los autores de los artículos: página 24, 1 (Steele, James: Eames House. Charles and Ray Eames. London: Phaidon Press Limited, 1994. pp. 30. Copyright Eames Office); página 25, 2 y 3 (Steele, James: ibid, pp 46 y 41. Copyright Eames Office); página 26, 4 (Steele, James: ibid, pp 37. Copyright Eames 0ffice), 5, 6, 7 (Neuhart Marilyn and John: Eames House. Berlin: Ernst\&Sohn Verlag für Architektur und technische Wissenschaften GmbH, 1994. pp 59, 48, 63. Copyright John, Marilyn, Andrew Neuhart and Julius Shulman, Arts\&Architecture magazine, Herman Miller, Inc, and Hap Johnson, and Eames Office); página 27, 8 y 9 (Van der Heuvel, Dirk \& Risselada, $\operatorname{Max}(\mathrm{Ed})$ : Alison and Peter Smithson -from the house of the Future to a house of today. Rotterdam: 010 Publishers, 2004. pp.156. Copyright Max Risselada and the Smithson Family Collection); página 28, 10 y 11 (Van der Heuvel, Dirk \& Risselada, Max (Ed): Ibid pp.156 y 162 respectivamente. Copyright Max Risselada and the Smithson Family Collection); página 30, 12 ( Van der Heuvel, Dirk \& Risselada, Max (Ed): Ibid pp. 161. Copyright Max Risselada and the Smithson Family Collection); página 31, 13 y 14 (Van der Heuvel, Dirk \& Risselada, Max (Ed): Ibid pp. 159. Copyright Max Risselada and the Smithson Family Collection); página 36, 1 a 3 (DVD Plans vol.3. París: Fondation Le Corbusier, 2005); página 38, 4 (DVD Plans vol.3. París: Fondation Le Corbusier, 2005), página 39, 5 (Fonds Jean Prouvé at the Archives Départamentales de Meure-et-Moselle), 6 (DVD Plans vol.3. París: Fondation Le Corbusier, 2005); página 40, 7 (DVD Plans vol.3. París: Fondation Le Corbusier, 2005), página 41, 8 y 9 (DVD Plans vol.3. París: Fondation Le Corbusier, 2005); página 42, 10 y 11 (DVD Plans vol.3. París: Fondation Le Corbusier, 2005); página 43, 12 y 13 (Fonds Jean Prouvé at the Archives Départamentales de Meureet-Moselle); página 44, 14 (DVD Plans vol.3. París: Fondation Le Corbusier, 2005); página 45, 15 (DVD Plans vol.3. París: Fondation Le Corbusier, 2005 ); página 46, 16,17 y 18 (DVD Plans vol.3. París: Fondation Le Corbusier, 2005); página 47, 19 (DVD Plans vol.3. París: Fondation Le Corbusier, 2005$)$, 20 (DVD Plans vol.4. París: Fondation Le Corbusier, 2005); página 51, 1 (Albrecht, Donald (Ed.): World War Il and the American Dream: How Wartime Building Changed a Nation. Cambridge (Massachusetts): The MIT Press, 1995, p. 36), página 52, 2 (Albrecht, Donald (Ed.): World War Il and the American Dream: How Wartime Building Changed a Nation. Cambridge (Massachusetts): The MIT Press, 1995, p. xxi); página 55, 3 (Smith, Elizabeth A.T. (Ed.): Blueprints for Modern Living: History and Legacy of the Case Study Houses. Cambridge (Massachusetts): The MIT Press, 1999, p. 14. Cortesía de Eames Office, Venice, California), 4 (Entenza, John D.: "The Case Study House Program". Arts \& Architecture. Enero 1945, p. 37. Reproducido con permiso, cortesía de David Travers); página 56, 5 (Entenza, John D.(Ed.): Arts \& Architecture. Julio 1945, p. 15. Reproducido con permiso, cortesía de David Travers); página 58, 6 (Entenza, John D.(Ed.): Arts \& Architecture. Abril 1945, p. 20. Reproducido con permiso, cortesía de David Travers), 7 (Entenza, John D.(Ed.): Arts \& Architecture. Marzo 1945, p. 26. Reproducido con permiso, cortesía de David Travers); página 59, 8 (Entenza, John D.(Ed.): Arts \& Architecture. Mayo 1948, p. 42. Reproducido con permiso, cortesía de David Travers), 9 (Entenza, John D.(Ed.): Arts \& Architecture. Junio 1950, p. 47. Reproducido con permiso, cortesía de David Travers); página 60, 10 (Entenza, John D.(Ed.): Arts \& Architecture. Mayo 1945, p. 13. Reproducido con permiso, cortesía de David Travers); página 61, 11 (Smith, Elizabeth A.T. (Ed.): Blueprints for Modern Living: History and Legacy of the Case Study Houses. Cambridge (Massachusetts): The MIT Press, 1999, p. 182. Cortesía de Eames Office, Venice, California), 12 (Entenza, John D.(Ed.): Arts \& Architecture. Julio 1949, p. 4. Reproducido con permiso, cortesía de David Travers); página 62, 13 (Shulman, Julius. Publicado en SMITH, Elizabeth A.T:: Case Study Houses. The Complete CSH Program (1945-1966). Köln: Taschen, 2009, p. 317. ( ) J. Paul Getty Trust. Used with permission. Julius Shulman Photography Archive. Research Library at the Getty Research Institute); página 65, 1 (G0-DB arquitectos asociados. Arquitectura. No 184. 1974. Madrid: Edita el Colegio de Arquitectos de Madrid Madrid); página 66, 2 (Informes de la Construcción. N. 309. Abril 1979. Madrid: Instituto Eduardo Torroja de la Construcción y del Cemento. 1979. pp. 45 a 60), 3 (Martínez García-Ordóñez, Fernando: Experimentación de GO-DB-Arquitectos Asociados con Módulos Tridimensionales. I Sector Monográficos sobre construcción industrializada Ciclo de Conferencias. Madrid: Sindicato Nacional de la Construcción. Gabinete Técnico. Publicaciones del Departamento de Industrialización, 1973. pp. 27-44); página 68, 4 a 7 (Martínez García-Ordóñez, Fernando: SIC. Proceso investigativo. Memoria final de la Beca de la Fundación March. Madrid: 1968); página 70, 8 a 11 (G0-DB Arquitectos asociados: Sistema Industrial de Construcción. El Instalador. № 18. Diciembre 1968. pp. 97-100); página 71, 12 (Martínez García-Ordóñez, Fernando: SIC. Proceso investigativo. Memoria final de la Beca de la Fundación March. Madrid: 1968), 13 (Martínez García-Ordóñez, Fernando: Archivo personal), 14 (Martínez García-Ordóñez, Fernando: Los espacios modulares unitarios pueden ser el futuro de la arquitectura. Arte y Cemento. №. 1.025. Marzo 1974. Bilbao: Eduardo González del Castillo. pp. 36-52); página 72,15 (dibujo Francisco Javier Cortina Maruenda); página 74, 16 y 17 (Martínez García-Ordóñez, Fernando: SIC. Proceso investigativo. Memoria final de la Beca de la Fundación March. Madrid: 1968), página 75, 18, 19 (Martínez García-Ordóñez, Fernando: SIC. Proceso investigativo. Memoria final de la Beca de la Fundación March. Madrid: 1968$), 20$ (Martínez García-Ordóñez, Fernando: Archivo personal); página 76, 21 a 23 (Martínez García-Ordóñez, Fernando: SIC. Proceso investigativo. Memoria final de la Beca de la Fundación March. Madrid: 1968); página 77, 24 y 25 (Martínez García-Ordóñez, Fernando: SIC. Proceso investigativo. Memoria final de la Beca de la Fundación March. Madrid: 1968 ); página 83, 1 (Domus. № 403. Junio 1963), 2 (Archivo Bruno Morassutti (fondos del Archivio Progetti del IUAV). Publicada en Barazzeta, Giulio; Dulio, Roberto: Bruno Morassutti 1920-2008. Opere e progetti. Milán: Mondadori Electa, 2009. pp. 144); página 84, 3 (Le Corbusier: Textes et planches. París: Vincent, Fréal \& Cie., 1960. pp. 161), 4 (dibujo Antonio Rueda Sánchez-Jáuregui, basado en documento de Archivo Bruno Morassutti (fondos del Archivio Progetti del IUAV). Publicada en Barazzeta, Giulio; Dulio, Roberto: Bruno Morassutti 1920-2008. Opere e progetti. Milán: Mondadori Electa, 2009. pp. 145); página 85, 5 y 6 (Fotos Estudio Morassutti y Giorgio Casali. Archivo Bruno Morassutti (fondos del Archivio Progetti del IUAV)); página 86, 7 (Foto Giorgio Casali. Archivo Bruno Morassutti) fondos del Archivio Progetti del IUAV)); página 87, 8 (Foto Giorgio Casali. Archivo Bruno Morassutti (fondos del Archivio Progetti del IUAV)), 9 (Archivo Aldo Favini); página 88, 10 (dibujo Rosario Barragán González, basado en documento de Archivo Bruno Morassutti (fondos del Archivio Progetti del IUAV). Publicada en Barazzeta, Giulio; Dulio, Roberto: Bruno Morassutti 1920-2008. Opere e progetti. Milán: Mondadori Electa, 2009. pp. 175); página 89, 11 (Archivo Bruno Morassutti (fondos del Archivio Progetti del IUAV). Publicada en Barazzeta, Giulio; Dulio, Roberto: Bruno Morassutti 1920-2008. Opere e progetti. Milán: Mondadori Electa, 2009. pp. 175); página 90, 12 (Dibujo de Carlos hurtado Bocanegra, basado en documento de Archivo Bruno Morassutti (fondos del Archivio Progetti del IUAV). Publicada en Barazzeta, Giulio; Dulio, Roberto: Bruno Morassutti 1920-2008. Opere e progetti. Milán: Mondadori Electa, 2009. pp. 178), 13 (Foto Gianni Berengo Gardin. Archivo Bruno Morassutti (fondos del Archivio Progetti del IUAV). Publicada en Barazzeta, Giulio; Dulio, Roberto: Bruno Morassutti 1920-2008. Opere e progetti. Milán: Mondadori Electa, 2009. pp. 177.), 14 (Archivo Bruno Morassutti (fondos del Archivio Progetti del IUAV); página 92, 15 (Diapositiva original de Bruno Morassutti. Archivo Bruno Morassutti (fondos del Archivio Progetti del IUAV)); páginas 97 a 112, 1 a 18 (dibujos de Elena Corres Álvarez); 116, 1 (Von Vegesack, Alexander y Remmele, Mathias (Ed.): Marcel Breuer. Design and Architecture. Weil am Rhein: Vitra Design Stiftung gGmbH, 2003); página 117, 2 (Smith, Elizabeth A. T.: Case Study Houses. The complete CSH program. $1945-1966$. Köln: Taschen GmbH, 2002), 3 (Mccoy, Esther: The Second Generation. Salt Lake City: Gibbs M. Smith, Inc., 1984); página 118, 4 (Boyce, Robert: Keck \& Keck. New York: Princeton Architectural Press, Inc., 1993), 5 y 6 ( Cygelman, Adèle: Palm Springs Modern. New York: Rizzoli International Publications, Inc., 1999), 7 (Wagener, Wolfgang: Raphael Soriano. New York: Phaidon Press Inc., 2002); página 119, 8 (Ambasz, Emilio (Ed.): Italy: the new domestic landscape. New York: The Museum of Modern Art, 1972); página 120, 9 (Smith, Elizabeth A. T. (Ed.): Blueprints for modern living. History and Legacy of the Case Study Houses. Cambridge, Massachusetts: The MIT Press, 1998); página 121, 10 (Bell, Eugenia (Ed.): Shigeru Ban. Nueva York: Princeton Architectural Press, 2001); página 122, 11 (Francisco Javier Terrados Cepeda); página 123, 12 (Francisco Javier Terrados Cepeda); página 124, 13 y 14 (Fernando Alda), 15 (Francisco Javier Terrados Cepeda); página 126, 16 (Fernando Alda), 17 (Francisco Javier Terrados Cepeda); página 127, 18 (Francisco Javier Terrados Cepeda. 